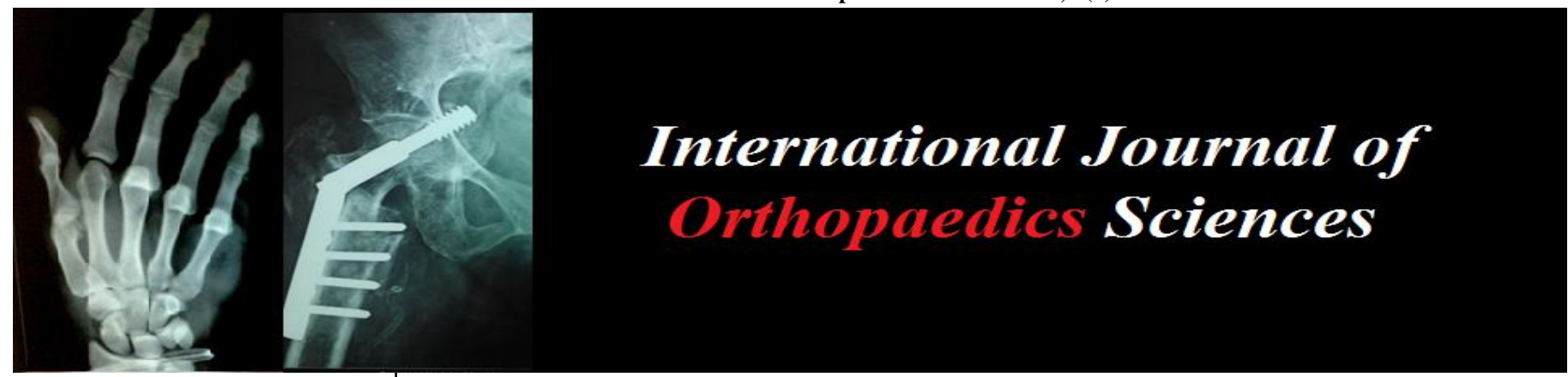

ISSN: $2395-1958$

IJOS 2018; 4(2): 518-524

(C) 2018 IJOS

www.orthopaper.com

Received: 20-02-2018

Accepted: 21-03-2018

Dr. Dayanand B Banapatti

Department of Orthopaedics,

Shri B M Patil Medical College and Research Centre, BLDE

University, Vijayapura,

Karnataka, India

Dr. Vinaykumar Babaleshwar Department of Orthopaedics, Shri B M Patil Medical College and Research Centre, BLDE

University, Vijayapura,

Karnataka, India

Dr. Santosh S Nandi

Department of Orthopaedics, Shri B M Patil Medical College and Research Centre, BLDE

University, Vijayapura,

Karnataka, India

Dr. Tapan Gupta

Department of Orthopaedics, Shri B M Patil Medical College and Research Centre, BLDE

University, Vijayapura,

Karnataka, India

Dr. Vijaykumar Patil

Department of Orthopaedics, Shri B M Patil Medical College and Research Centre, BLDE

University, Vijayapura,

Karnataka, India
Correspondence

Dr. Vinaykumar Babaleshwar Department of Orthopaedics, Shri B M Patil Medical College and Research Centre, BLDE

University, Vijayapura,

Karnataka, India

\section{Treatment of intraarticular distal end radius fractures by ligamentotaxis: A prospective study}

\author{
Dr. Dayanand B Banapatti, Dr. Vinaykumar Babaleshwar, Dr. Santosh S \\ Nandi, Dr. Tapan Gupta and Dr. Vijaykumar Patil
}

DOI: $\underline{\text { https://doi.org/10.22271/ortho.2018.v4.i2h.80 }}$

\section{Abstract}

Fractures of distal end radius are common fractures of the upper limb, and constitute $17 \%$ of all fractures and $75 \%$ of all forearm fractures 1 .

This fracture shows bimodal distribution of age with the fracture more commonly seen in children and elderly.

The objectives of management for a distal end radius fracture should be restoration of range of motion and grip strength while facilitating the patient's early reinstation to normal daily activities and minimizing the chances of post traumatic arthritis. The treating orthopedician has an armada of treatment options to select from to accomplish this. Regardless of these fractures being common, there is no clear consensus on their treatment as there is no clear clinical-based evidence in the literature. For several decades, closed reduction and bridging external fixator for 4-6 weeks has been a well-established treatment of distal end radius fracture7. To reduce fracture fragments and maintain alignment, principle of ligamentotaxis is used by external fixation. This study aims to assess the functional outcome and duration for union in intraarticular distal radius fractures treated with external fixator using ligamentotaxis. The present study was carried out from 1ST December 2015 to 31ST January 2017 at Orthopaedic Department in Shri B. M. Patil Medical College Hospital and Research Center, Vijayapur. During this period 100 patients of intraarticular communited distal end radius fractures were treated surgically. We found 78\% Excellent to Good results. 14 patients had Fair results while 8 patients had Poor results. Most common complication seen in our study were Pin Tract Infection (12\%) and Restricted Wrist Motion (5\%). It was concluded that external fixation offers good mode of treatment in communited fractures as they allow gradual distraction providing better functional and anatomical results in communited intraarticular wrist injuries.

Keywords: Intraarticular distal, radius fractures, ligamentotaxis

\section{Introduction}

Fractures of distal end radius are common fractures of the upper limb, and constitute $17 \%$ of all fractures and $75 \%$ of all forearm fractures ${ }^{[1]}$.

This fracture shows bimodal distribution of age with the fracture more commonly seen in children and elderly. Reduced amount of stronger cortical bone and increased amount of weaker cancellous bone at the metaphyseal broad area of distal radius predisposes to distal end radius fracture. Osteoporosis and tendency to fall on outstretched hand constitute major risk factors ${ }^{[2]}$. Falls on outstretched hand results frequently in a distal radius fracture. In an active and independent individual, wrist fracture indicates early manifestation of osteoporosis which predicts hip fracture in later years ${ }^{[3]}$. The societal burden of these fractures increases in the future as the aging population grows rapidly. Therefore, in perspective of patients and the society, it is important to study the epidemiology and treatment of these fractures to optimize outcome.

The objectives of management for a distal end radius fracture should be restoration of range of motion and grip strength while facilitating the patient's early reinstation to normal daily activities and minimizing the chances of post traumatic arthritis. The treating orthopedician has an armada of treatment options to select from to accomplish this. Regardless of these fractures being common, there is no clear consensus on their treatment as there is no clear clinical-based evidence in the literature. 
Non-operative management is reserved for undisplaced stable fractures and require no fixation ${ }^{[6]}$. Symptomatic relief is achieved by immobilization with below elbow cast. In intraarticular, unstable fractures, operative fixation is imperative in maintaining an acceptable reduction. Various methods for surgical management are available. Operative management of fracture include closed, or open reduction.

For several decades, closed reduction and bridging external fixator for 4-6 weeks has been a well-established treatment of distal end radius fracture ${ }^{[7]}$. To reduce fracture fragments and maintain alignment, principle of ligamentotaxis is used by external fixation. After removal of external fixator, it is possible that there may be redisplacement of fracture fragments $^{8}$. Pin site infection, radial nerve lesions, pin loosening, iatrogenic fracture, redisplacement and complex regional pain syndrome (CRPS) ${ }^{[9]}$ are known complication of external fixation. Non-bridging external fixation is favourable for rehabilitation as it allows wrist mobilization during the fixation ${ }^{[10]}$ though it requires a sizable distal fracture fragment. It has been concluded in Cochrane review that there is not enough proof to conclude the relative effects of the different methods of external fixation ${ }^{[11]}$. Percutaneous pinning and cast following closed reduction is another commonly used modality of treament. $\mathrm{K}$ wires can be inserted by an array of techniques; across fracture site in crossed manner or using intrafocal Kampandji technique [12]. Percutaneous pinning is indicated for non-communited extraarticular fractures. Complications of $\mathrm{K}$ wiring and external fixation are similar. Temporary wrist stiffness following a similar period of immobilization have been observed in both the methods. Both methods are often combined. The percutaneous pins fixation provides additional stability [13], especially in intra-articular fractures where pins augment the reduction of intra-articular displacement ${ }^{[14]}$. For the management of unstable, dorsally displaced, fractures of distal radius, open reduction and internal fixation using volar locked plates have gained popularity in recent times and has shown promising results in patients of varied ages $[15,16,17]$. External fixation or percutaneous pinning are less invasive and cheaper as compared to volar plating. The advantage of volar plating is that it provides exact reduction of fracture fragments and allowing immediate functional loading of wrist. Flexor and extensor tendon irritations and ruptures, carpal tunnel syndrome, fracture redisplacement, screw loosening and CRPS ${ }^{[18]}$ are the complications associated with volar plate. Since the introduction of volar plates the use of Dorsal (buttress) plating has become almost obsolete. There has been good results for dorsal plate has been reported for communited fractures ${ }^{[19]}$ but it carries significant risk of extensor tendon injuries ${ }^{[20]}$. Low profile fragment specific plates have been introduced recently has been assessed by authors [21, 22]. Promising results have been reported for intramedullary fixation devices which uses subchondral screws for locing in the stem ${ }^{[23]}$. Dorsal bony defects can be filled with bone grafts, principally in osteoporotic bone. While bone grafting may improve anatomical results but it is yet to be proven that it contributes to improvement of final functional results ${ }^{[24]}$. Several studies comparing dorsal plating ${ }^{[25,26]}$, fragment specific systems ${ }^{[23]}$, or a mixture of dorsal and volar plating techniques [27, 28]. with external fixation, however, these studies have not shown considerable evidence to support the use of one method over the other. Studies comparing volar locked plating with external fixation, have not given suggestion of superiority for either method over the other ${ }^{[29,30,31]}$. External fixation has been reported to be superior ${ }^{[32,33]}$ and beneficial in the long term ${ }^{[34]}$ and shows similar results when compared to percutaneous pinning [35].

\section{Aims and Objectives}

To study the functional outcome and duration for union in intraarticular distal radius fractures treated with external fixator using ligamentotaxis.

\section{Methodology}

The present study was carried out from $1^{\mathrm{ST}}$ December 2015 to $31^{\text {ST }}$ January 2017 at Orthopaedic Department in Shri B. M. Patil Medical College Hospital and Research Center, Vijayapur. During this period 100 patients of intraarticular communited distal end radius fractures were treated surgically.

\section{Inclusion criteria}

1. Patient aged 18 years and above.

2. Intraarticular fractures of distal radius.

3. Communited fractures of distal radius.

4. Open fractures of distal radius.

5. Patients willing for treatment and giving informed and written consent.

\section{Exclusion criteria}

1. Patients below the age of 18 years.

2. Pathological fractures.

3. Neurovascular deficit

\section{Surgical technique}

i. About $1 \mathrm{~cm}$ incision was made just dorsal to midline, 8$10 \mathrm{~cm}$ proximal to wrist.

ii. Two 3.5-mm half-pins, $1 \mathrm{~cm}$ apart at a 30-degree angle dorsal to the frontal plane of the forearm were inserted. The pins should perforate the medial cortex of the radius confirmed with fluoroscopy.

iii. A 2- to 3-cm incision over the dorsoradial aspect of the index metacarpal base and use blunt dissection with scissors to expose the metacarpal.

iv. 2.5-mm self-tapping half-pins at a 30- to 45-degree angle dorsal to the frontal plane of the hand and forearm were inserted and confirmed by fluoroscopy.

v. Reduction was achieved by traction and manipulation, confirmed by fluoroscopy.

vi. Shanz pins were connected with clamps and connecting rods.

vii. Wound irrigation was done and skin sutures were applied.

Patients were kept nil orally for 4 to 6 hours post-operatively. Intravenous fluids were given as needed. Antibiotics were continued for 10 days. The wound was inspected at $2^{\text {nd }}$ postoperative day. Rehabilitation of the affected wrist was started at the end of 2 weeks. Grip strength exercises were started. At 6 weeks gentle active range of motion of the wrist was allowed. At 6 to 8 weeks active range of motion in all planes were allowed. Regular follow up for every 6 weeks, 3 months and 6 months until radiological union was achieved.

\section{Results}

The increased incidence of male sex in distal end radius can be attributed to an over whelming large proportion of male patients, because in our Indian setup, the female population largely work indoors or in the agricultural fields.

In our series, the majority of the patients are found to be 
between the age group of 41-50 years (26) and 51-60 years (18). Majority of cases in our study attributed to Road Traffic Accidents $(66 \%)$. It is also worthwhile to note that most of fractures were seen in young active individuals were pertaining due to road traffic accidents while in age group above 50 years were due to self-fall experienced at home. Majority of cases being from Frykman 5 and 6(43\%) and the least being Frykman 8 (9\%). The type fracture depends upon mode of injury, age of patient and quality of bone. 2 patients had malunion with some degree of residual dorsal angulation however it did not have a significant effect on functional outcome. 2 patients had pin loosening which resolved without any intervention. 12 patients suffered from pin tract infection and superficial infection which was treated by regular dressing. 5 patients had residual wrist pain after 2 months after external fixator removal which was treated with analgesics and resolved by 6 months. 5 patients had restricted wrist motion 2 months after external fixation removal which was treated with aggressive physiotherapy and analgesics and was resolved with 1 month of physiotherapy. We found $78 \%$ Excellent to Good results. 14 patients had Fair results while 8 patients had Poor results. Most common complication seen in our study were Pin Tract Infection (12\%) and Restricted Wrist Motion (5\%). It was also noted that as the severity of fracture increased, so did the rate of complications. So while fractures with Frykman 3-4 had 2\% complications and Frykman 7-8 had complications in 16 cases. While patients with Frykman $3-4(84.8 \%)$ and Frykman 5-6(70.5\%) had union in 6 weeks, patients with Frykman 7-8 fractures had average time of union of 8 weeks $(69.6 \%)$.

\section{Discussion}

This is a short term study which with mean follow-up of 18.2 months so this is a preliminary study. The aim of the following study is to evaluate the functional outcome of treatment of intra-articular, communited and compound distal radius fractures using ligamentotaxis. From $1^{\text {ST }}$ December 2015 to $31^{\text {ST }}$ January 2017 we treated 100 intraarticular distal radius fractures were treated with spanning external fixator with or without augmentation with $\mathrm{K}$ wires. Mean age in most studies shows the increased incidence of intraarticular fractures in the $4^{\text {th }}$ decade of life. This attributes mostly to active lifestyle which is more prone to high velocity injuries such as road traffic accidents. High incidence of males having intraarticular distal radius fractures is evident in other studies. Of 100 patients, $66 \%$ of fractures were attributed to RTA, $29 \%$ patients were attributed to self-fall and $5 \%$ of injuries were due to assault. Deepak CD et al. ${ }^{[42]}$ and Gunaki et al. ${ }^{[52]}$ reported similar results in their studies.

While comparing the distribution of fractures in our study, the results were comparable to that in other studies. Most of the cases in our study were of Type IV-V (42\%). Discrepancy of results in our study to that of some studies can be attributed to difference in number of cases included in their studies $[44,57,51$, 56]. Majority of cases achieved union within 6 weeks $(62 \%)$ while longest period for achieving union which was 10 weeks was seen in 2 cases. Most common complication seen in our study were Pin Tract Infection(12\%) and Restricted Wrist Motion(5\%). 3 patients had residual pain which was treated by analgesics, but the pain was not as disabling enough to hinder daily activities of patient. 1 patient developed mild form of Sudeck's Dystrophy which subsided on eventual follow up with conservative management. None of patients reported non-union. Complications in our study were comparable with previous studies ${ }^{[49,44,51,52,53,54]}$.

De merit system of Gartland and Werley were used to assess functional outcome at 6 months follow up. Poor functional outcome was seen in open fractures and severe communition owing to severe damage to surrounding soft tissues. The results in our study were comparable to standard studies ${ }^{[54]}$.

\section{Case 1}

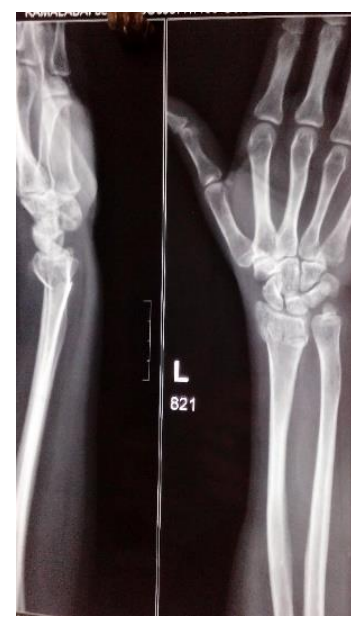

Preoperative X-ray

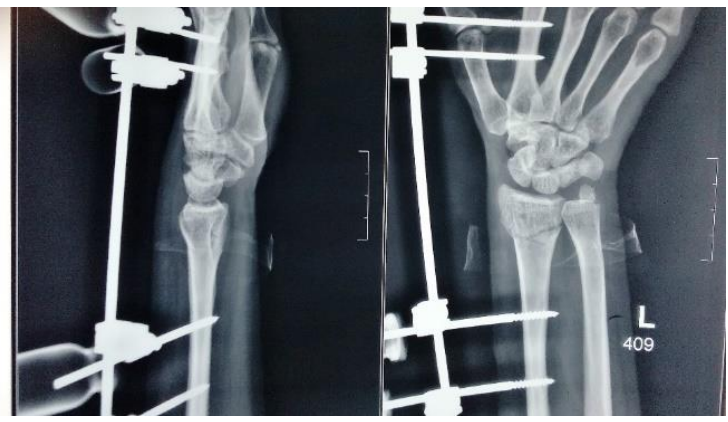

Post-Operative X-Ray

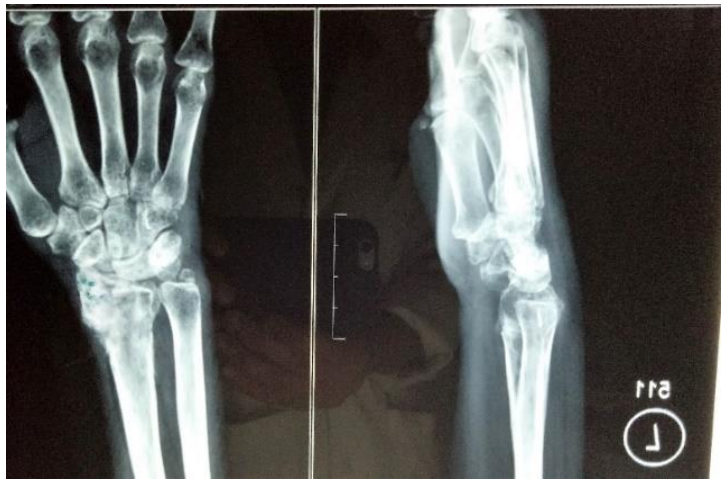

Follow Up At 6 Months 


\section{Clinical Photographs}
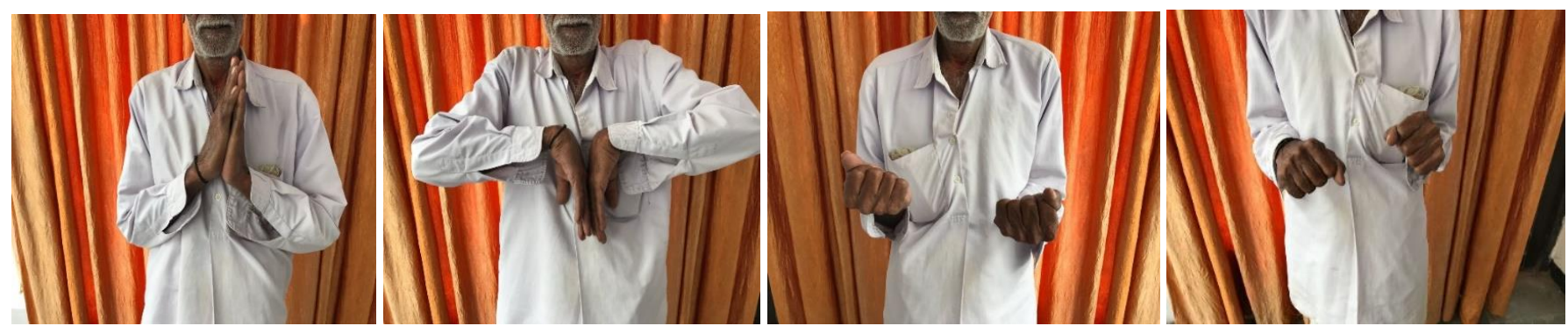

Case 2
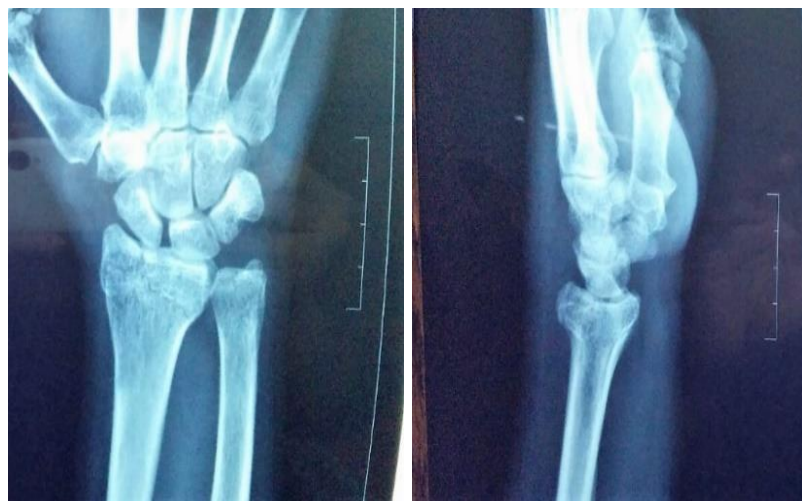

Preoperative X-ray

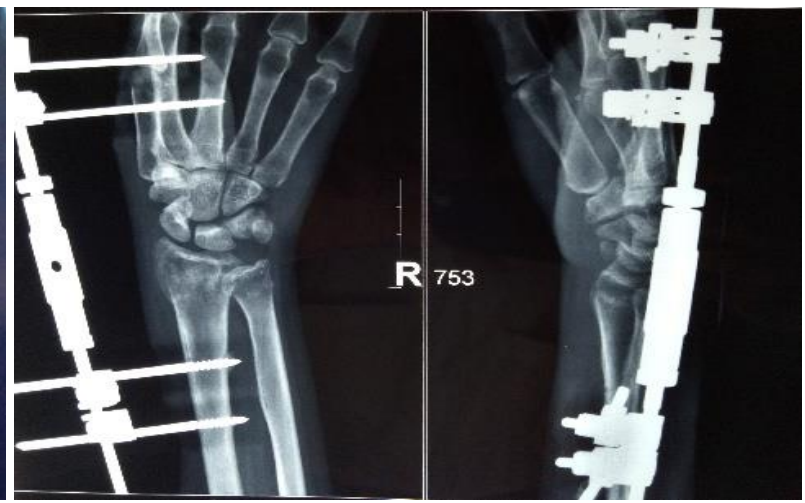

Post Operative X-Ray

Clinical photographs
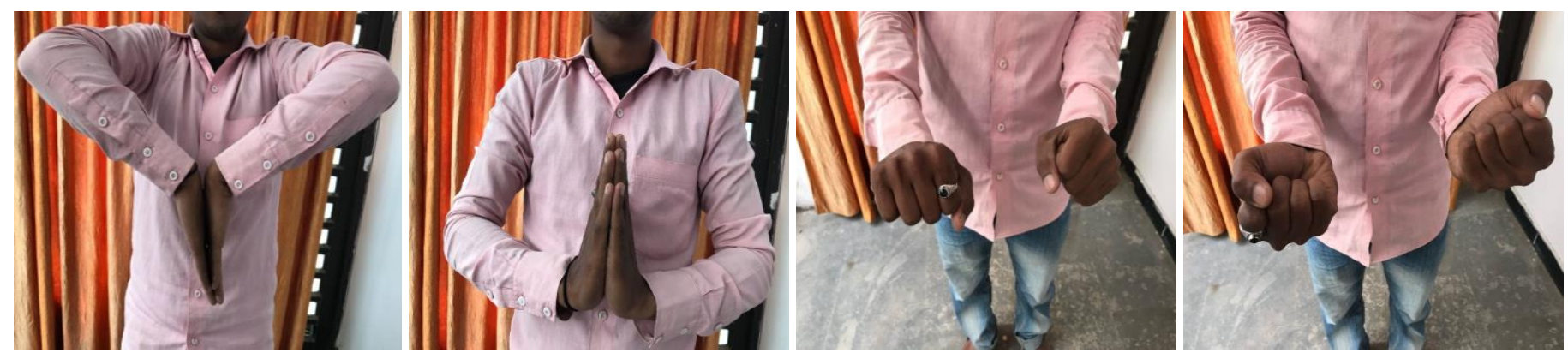

Case 3

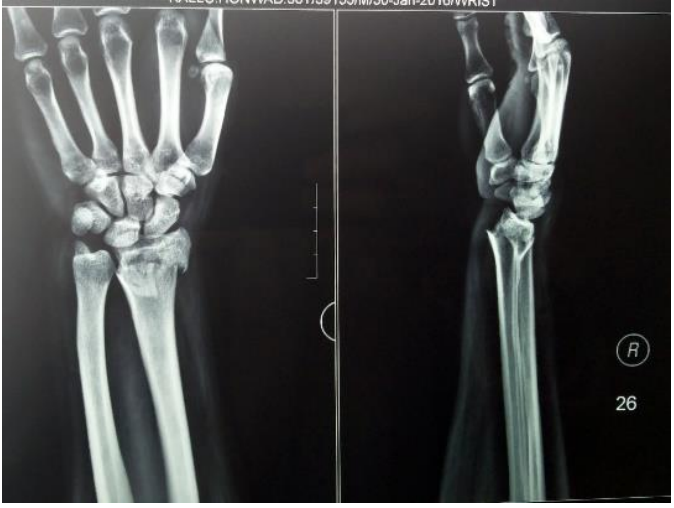

Preoperative Xray

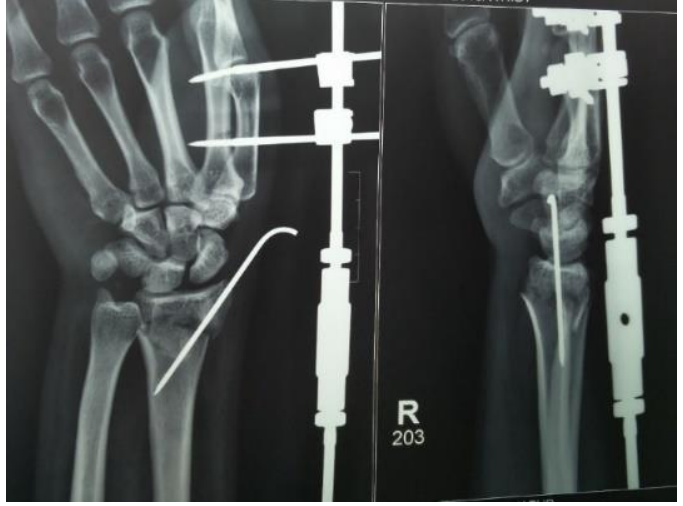

Post Operative Xray 


\section{Clinical Pictures}
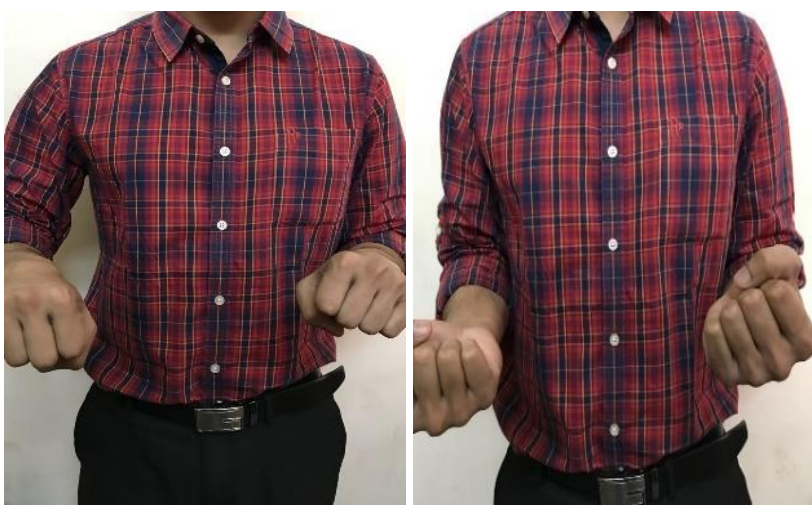

\section{Conclusion}

By observing the results of our study with standard studies following conclusions are drawn-

1) External fixation offers good mode of treatment in communited fractures as they allow gradual distraction providing better functional and anatomical results in communited intraarticular wrist injuries. It provided early mobilization and reduces edema stiffness of joints thus leading to better and early functional recovery.

2) External fixation allows wound observation and coverage procured during open fractures without compromising the reduction achieved

3) It is an incomplete solution to treatment of intraarticular fractures and may be augmented by percutaneous $\mathrm{K}$ wires.

The final functional result of treatment of distal radius fractures not only depends on the anatomical restoration of the articular surface but also on the associated soft tissue injuries and articular damage.

\section{References}

1. Margaret McQueen M, Rockwood CA. Fractures of the distal radius and ulna. Chapter-32, In: Rockwood CA, Matsen FA, Wirth MA, Lippitt SB, editors, Upper Extremity. 3rd edition Philadelphia: Saunders, 2004, 455519.

2. Vogt MT, Cauley JA, Tomaino MM, Stone K, Williams JR, Herndon JH. Distal radius fractures in older women: A 10-year follow-up study of descriptive characteristics and risk factors. The study of osteoporotic fractures. J Am Geriatr Soc. 2002; 50(1):97-103.

3. Bengnér $U$, Johnell 0. Increasing incidence of forearm fractures. A comparison of epidemiologic patterns 25 years apart. Acta Orthop Scand. 1985; 56:158-60.

4. Colles A. The classic: On the fracture of the carpal extremity of the radius (reprinted from original 1814 article). Clin Orthop. 1972; 83:3-5.

5. Schmalholz A. Epidemiology of distal radius fracture in Stockholm 1981-82. Acta Orthop Scand. 1988; 59(6):701-3.

6. Abbaszadegan H, Conradi P, Jonsson U. Fixation not needed for undisplaced Colles' fracture. Acta Orthop Scand. 1989a; 60(1):60-2.

7. Cooney WP, Linscheid RL, Dobyns JH. External pin fixation for unstable Colles' fractures. J Bone Joint Surg (Am). 1979; 61:840-5.

8. Dicpinigaitis P, Wolinsky P, Hiebert R, Egol K, Koval K, Tejwani N. Can external fixation maintain reduction after distal radius fractures? J Trauma. 2004; 57(4):845-50.

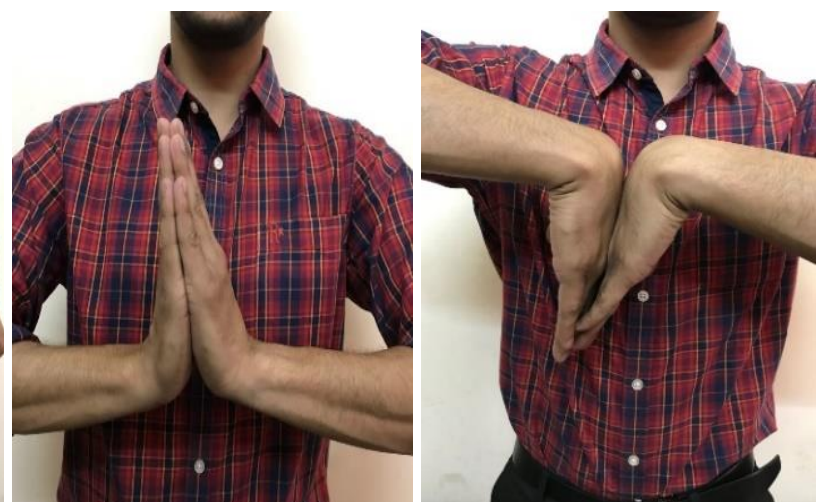

9. Pennig D, Gausepohl T. External fixation of the wrist. Injury. 1996; 27(1):1-15.

10. McQueen MM. Redisplaced unstable fractures of the distal radius. A randomised, prospective study of bridging versus non-bridging external fixation. J Bone Joint Surg (Br). 1998; 80(4):665-9.

11. Handoll HHG, Madhok R. Closed reduction methods for treating distal radial fractures in adults. Cochrane Database of Systematic Reviews 2003a, 1. Art. No.: CD003763. DOI: 10.1002/14651858.CD003763.

12. Harley BJ, Scharfenberger A, Beaupre LA, Jomha N, Weber DW. Augmented external fixation versus percutaneous pinning and casting for unstable fractures of the distal radius - a prospective randomized trial. J Hand Surg (Am). 2004; 29(5):815-24.

13. Dunning CE, Lindsay CS, Bicknell RT, Patterson SD, Johnson JA, King GJW. Supplemental pinning improves the stability of external fixation in distal radius fractures during simulated finger and forearm motion. J Hand Surg (Am). 1999; 24:992-1000.

14. Trumble TE, Wagner W, Hanel DP, Vedder NB, Gilbert M. Intrafocal (Kapandji) pinning of distal radius fractures with and without external fixation. J Hand Surg (Am). 1998; 23(3):381-94.

15. Orbay JL, Fernandez DL. Volar fixed-angle plate fixation for unstable distal fractures in the elderly patient. J Hand Surg (Am). 2004; 29:96-102.

16. Chung KC, Shauver MJ, Birkmeyer JD. Trends in the United States in the treatment of distal radial fractures in the elderly. J Bone Joint Surg (Am). 2009; 91:1868-73.

17. Jupiter JB, Marent-Huber M. LCP Study Group. Operative management of distal radial fractures with 2.4millimeter locking plates. A multicenter prospective case series. J Bone Joint Surg (Am). 2009; 91(1):55-65.

18. Arora R, Lutz M, Hennerbichler A, Krappinger D, Espen D, Gabl M. Complications following internal fixation of unstable distal radius fracture with a palmar lockingplate. J Orthop Trauma. 2007; 21(5):316-22.

19. Rozental TD, Blazar PE, Franko OI, Chacko AT, Earp BE, Day CS. Functional outcomes for unstable distal radial fractures treated with open reduction and internal fixation or closed reduction and percutaneous fixation. A prospective randomized trial. J Bone Joint Surg (Am). 2009; 91(8):1837-46.

20. Grewal R, MacDermid JC. The risk of adverse outcomes in extra-articular distal radius fractures is increased with malalignment in patients of all ages but mitigated in older patients. J Hand Surg (Am). 2007; 32(7):962-70.

21. Konrath GA, Bahler S. Open reduction and internal fixation of unstable distal radius fractures: Results using 
the trimed fixation system. J Orthop Trauma. 2002; 16(8):578-85.

22. Abramo A, Kopylov P, Geijer M, Tägil M. Open reduction and internal fixation compared to closed reduction and external fixation in distal radial fractures: A randomized study of 50 patients. Acta Orthop. 2009; 80(4):478-85.

23. Nishiwaki M, Tazaki K, Shimizu H, Ilyas AM. Prospective study of distal radial fractures treated with an intramedullary nail. J Bone Joint Surg (Am). 2011; 93:1436-41.

24. Tosti R, Ilyas AM. The role of bone grafting in distal radius fractures. J Hand Surg (Am). 2010; 35:2082-4.

25. Grewal R, MacDermid JC. The risk of adverse outcomes in extra-articular distal radius fractures is increased with malalignment in patients of all ages but mitigated in older patients. J Hand Surg (Am). 2007; 32(7):962-70.

26. Kateros K, Macheras G, Galanakos SP, Sofianos I, Papakostas I, Papadakis SA. External fixation versus "pi" plate for distal radius fractures. J Trauma. 2010; 68(1):166-72.

27. Kreder HJ. Hanel DP, McKee M, Jupiter J, McGillivary $\mathrm{G}$, Swiontkowski MF. Consistency of the AO fracture classification for the distal radius. J Bone Joint Surg (Br). 1996a; 78:726-31.

28. Leung F, Tu YK, Chew WY, Chow SP. Comparison of external and percutaneous pin fixation with plate fixation for intra-articular distal radial fractures. A randomized study. J Bone Joint Surg (Am). 2008; 90(1):16-22.

29. Wright TW, Horodyski MB, Smith DW. Functional outcome of unstable distal radius fractures: ORIF with a volar fixed-angle tine plate versus external fixation. J Hand Surg (Am). 2005; 30:289-99.

30. Egol K, Walsh M, Tejwani N, McLaurin T, Wynn C, Paksima N. Bridging external fixation and supplementary Kirschner-wire fixation versus volar locked plating for unstable fractures of the distal radius: A randomised, prospective trial. J Bone Joint Surg (Br). 2008; 90(9):1214-21.

31. Rizzo M, Katt BA, Carothers JT. Comparison of locked volar plating versus pinning and external fixation in the treatment of unstable intraarticular distal radius fractures. Hand (N Y). 2008; 3(2):111-7.

32. Wei DH, Raizman NM, Bottino CJ, Jobin CM, Strauch RJ, Rosenwasser MP. Unstable distal radius fractures treated with external fixation, a radial column plate, or a volar plate. J Bone Joint Surg (Am). 2009; 91(7):1568-77.

33. Oshiege T, Sakai A, Zenke Y, Moritani S, Nakamura T. A comparative study of clinical and radiological outcomes of dorsally angulated, unstable distal radius fractures in elderly patients: Intrafocal pinning versus volar locking plating. J Hand Surg (Am). 2007; 32:138592.

34. McFadyen I, Field J, McCann P, Ward J, Nicol S, Curwen C. Should unstable extra-articular distal radial fractures be treated with fixed angle volar-locked plates or percutaneous Kirschner wires? A prospective randomised controlled trial. Injury. 2010; 42:162-6.

35. Rozental TD, Blazar PE, Franko OI, Chacko AT, Earp BE, Day CS. Functional outcomes for unstable distal radial fractures treated with open reduction and internal fixation or closed reduction and percutaneous fixation. A prospective randomized trial. J Bone Joint Surg (Am). 2009; 91(8):1837-46.

36. Zhang Q, Liu F, Xiao Z. Internal Versus External
Fixation for the Treatment of Distal Radial Fractures: A Systematic Review of Overlapping Meta-Analyses. Omboni. S, ed. Medicine. 2016; 95(9):e2945. doi:10.1097/MD.0000000000002945.

37. Sebastián-Castañón S, Fontaine-Guevara G, NegreteCorona J, Arteaga-Solís JR. Complex distal radius fractures in young patients. Comparison between external fixator and volar plate. Acta Ortop Mex. 2012; 26(5):298-302.

38. Yang X, Zhao YM, Chen L, Ye CC, Guo WJ, Wang B. Treatment type $\mathrm{C}$ fracture of the distal radius with locking compression plate and externalfixators. Zhongguo Gu Shang. 2013; 26(12):997-1001.

39. Praveen Anvekar M, Sachin Nimbargi S, Srinath SR, Anil Nelivigi S. Treatment of intra - articular fracture of distal radius with static external fixators - ligamentotaxis - A prospective study. Journal of Evolution of Medical and Dental Sciences. 2013; 2(32)12; 6026-6037.

40. Gradl G, Gradl G, Wendt M, Mittlmeier T, Kundt G, Jupiter JB. Non-bridging external fixation employing multiplanar K-wires versus volar locked plating for dorsally displaced fractures of the distal radius. Arch Orthop Trauma Surg. 2013; 133(5):595-602.

41. Shukla R, Jain RK, Sharma NK, Kumar R. External fixation versus volar locking plate for displaced intraarticular distal radius fractures: a prospective randomized comparative study of the functional outcomes. Journal of Orthopaedics and Traumatology: Official Journal of the Italian Society of Orthopaedics and Traumatology. 2014; 15(4):265-270.

42. Deepak CD, Gopalakrishna G, Ravoof A. Surgical management of distal end radius fractures by ligamentotaxis. Int J Health Sci Res. 2014; 4(4):106-110.

43. Asadullah Makhdoom, Asadullah M, Abdul P, Qureshi L, Kakar H, Raza $\mathrm{H}$ et al. Distal radius fractures managed by penning dynamic wrist fixator. 2014; 3:15-8.

44. Yalavarthi RK, Vishal A. Outcome of Management of Distal Radius Fractures by Ligamentotaxis. IOSR J Dent Med Sci Ver. 2015; 14(7):2279-861.

45. Singh H, Kaur D. Anatomical evaluation of fracture of distal radius treated by external fixator cum distractor. 2015; 2(6):33-8.

46. Bajwa AS, Rammappa M, Lee L, Nanda R. Treatment of unstable distal radius fractures: non-invasive dynamic external fixator versus volar locking plate - functional and radiological outcome in a prospective case-controlled series. SICOT-J. 2015; 1:34. doi:10.1051/sicotj/2015033.

47. Li-hai Z, Ya-nan W, Zhi M, Li-cheng Z, Hong-da L, Huan Y et al. Volar locking plate versus external fixation for the treatment of unstable distal radial fractures: a meta-analysis of randomized controlled trials. J Surg Res. 2015; 193:324-333. J Hand Surg Eur Vol. 2014; 39:249-257.

48. Sha L, Chen Q, Sun L. Effectiveness comparison of external fixation and volar locking compression plate in treatment of distal radius fractures of type C. Zhongguo Xiu Fu Chong Jian Wai Ke Za Zhi. 2015; 29(6):683-687.

49. Ma C, Deng Q, Pu H. External fixation is more suitable for intra-articular fractures of the distal radius in elderly patients. Bone Research. 2016; 4:16017. doi:10.1038/boneres.2016.17.

50. Tang Z, Liu J, Yang H. Comparison of outcome of VLCP versus PKEF in the treatment of AO type C2-3 distal radial fractures. Annals of Medicine and Surgery. 2017; 18:28-32. doi:10.1016/j.amsu.2017.05.006. 
51. Leung KS, Shen Wy, Leung PC, Kinnimonth AW, Chang JC, Chan GP. Ligamentotaxis and bone grafting for communited fractures of distal radius. J Bone Joint Surg. 1989; 71-B(5):838-842.

52. Gunaki RB, Ranka RP. Management of fractures of distal third of radius. Indian Journal Orthopaedics. 1998; 80$\mathrm{B}(4): 665-669$.

53. Kapoor H, Agarwal A, Dhaon BK. Displaced intraarticular fractures of distal radius: a comparitive evaluation of results following closed reduction, external fixation and open reduction with internal fixation. Injury Journal. 2000; 31:75-79.

54. Jain BK, Shukla J, Mehrotra A, Srivastava N. Treatment o communited fractures distal radius by ligamentotaxis. Indian Journal of Orthopaedics. 1998; 32(3):239-241.

55. Yamamoto K, Masaoka $\mathrm{T}$, Shishido $\mathrm{T}$, Imakiire $\mathrm{A}$. Clinical results of external fixation for unstable Colles' fractures. Hand Surg. 8(2):193-200.

56. Nagi ON, Dhillon MS, Aggarwal S, Deogaonkar KJ. External fixators for intra-articuar distal radius radius fractures. Indian Journal of Orthopaedics. 2004; 38:19-22.

57. Cooney WP, Linsheid RL, Dobyns JH. External Pin Fixation for Unstable Colles' Fracture. J Bone Joinr Surg. 1979; 61-A:840-845. 